\title{
The Correlation between Posterior Tibial Slope and Maximal Angle of Flexion after Total Knee Arthroplasty
}

\author{
Keong-Hwan Kim, MD, Seong-Il Bin, MD and Jong-Min Kim, MD \\ Department of Orthopedic Surgery, Asan Medical Center, Ulsan University College of Medicine, Seoul, Korea
}

Purpose: The purpose of this study was to evaluate the correlation between the posterior tibial slope and the maximal angle of flexion after total knee arthroplasty.

Materials and Methods: Seventy nine cases (63 patients, 60 females and 3 males), which received total knee arthroplasty with the Nexgen LPS system from Jan 2001 to Jan 2004, were enrolled. We divided all cases into two subsets in two ways. Firstly, group A (up to $10^{\circ}$, 44 cases) and group B (over $10^{\circ}, 35$ cases) were divided according to the mean value of the postoperative posterior tibial slope. Secondly, group a (up to $-4^{\circ}$, 39 cases) and group $\beta$ (over $-4^{\circ}, 40$ cases) were divided according to the mean difference between the preoperative posterior tibial slope and the postoperative posterior tibial slope. We compared the maximal angle of flexion between group A and group B, group $\alpha$ and group $\beta$, respectively.

Results: There was no significant difference between group A and group B, and also between group $\alpha$ and group $\beta$ in terms of maximal angle of flexion.

Conclusions: There was no significant correlation between the postoperative posterior tibial solpe and the maximal angle of flexion.

Key words: Osteoarthritis, Posterior tibial slope, Maximal angle of flexion, Total knee arthroplasty.

\section{Introduction}

Total knee arthroplasty (TKA) has been considered as a standard procedure for intractable pain in the end-stage degenerative arthritis of the knee ${ }^{1)}$. Development of a new method for significant increase in the maximal angle of flexion would be beneficial for the improvement in pain and function following $\mathrm{TKA}^{2)}$.

Postoperative range of motion (ROM) is determined by a

Received April 26, 2011; Revised (1st) June 7, 2011;

(2nd) September 20, 2011; (3rd) December 21, 2011;

Accepted July 6, 2012.

Correspondence to: Jong-Min Kim, MD.

Department of Orthopedic Surgery, Asan Medical Center, Ulsan

University College of Medicine, 88 Olympic-ro 43-gil, Songpa-gu, Seoul 138-736, Korea.

Tel: +82-2-3010-3897, Fax: +82-2-488-7877

Email: jmkim@amc.seoul.kr

This is an Open Access article distributed under the terms of the Creative Commons Attribution Non-Commercial License (http://creativecommons.org/licenses/by-nc/3.0/) which permits unrestricted non-commercial use, distribution, and reproduction in any medium, provided the original work is properly cited. variety of factors including preoperative flexion contracture, preoperative ROM, valgus/varus deformity, surgical technique, type and position of prosthesis ${ }^{3-12)}$. Proximal tibial cut angle and changes in the posterior tibial slope after surgery have also been associated with postoperative ROM in some studies ${ }^{13-21)}$.

Based on the results of previous studies using cadavers, computer models, or radiography, we hypothesized that the posterior tibial slope would be correlated with maximal angle of flexion $^{14,18,20)}$.

Although there are some studies that investigated the correlation in TKA patients, other variables were not sufficiently controlled in the study by Kansara and Markel ${ }^{19)}$ and the followup period was short (12 months) in the study by Malviya et al. ${ }^{21}$.

The purpose of this study was to assess the hypothesis that the posterior tibial slope would be positively correlated with the maximal angle of flexion in a more independent and accurate manner by controlling other ROM-related factors and involving $\geq 3$ years of follow-up.

\section{Materials and Methods}

\section{Study Subjects and Surgical Technique}

One hundred and two cases (75 patients, 71 females and 4 males), which were available for $\geq 3$ years of follow-up after TKA 
using the Nexgen LPS system (Zimmer, Warsaw, IN, USA), were initially included in this study. The surgery was performed due to degenerative arthritis by the same surgeon at our institution between January 2001 and January 2004.

Of the initial 102 cases, those that had far below/above the mean values for the factors that may influence the maximal angle of flexion except for the posterior tibial slope were excluded to eliminate the confounding variables. The mean preoperative flexion contracture was $11^{\circ}$ (range, $0^{\circ}-60^{\circ}$ ) in the 102 cases, 9 of which had $\geq 20^{\circ}$ of flexion contracture. The mean preoperative ROM was $114.2^{\circ}$ (range, $20^{\circ}-150^{\circ}$ ) in the 102 cases, 11 of which had $<90^{\circ}$ of ROM. The mean preoperative deformity was $11.8^{\circ}$ of varus (range, valgus $8^{\circ}$-varus $33^{\circ}$ ) in the 102 cases, 3 of which had valgus deformities and 6 of which had $\geq 20^{\circ}$ of varus deformity. A total of 23 cases that exhibited far below/above the mean values for at least one of the three factors were excluded from this study. The final number of included cases was 79 (63 patients, 60 females and 3 males). The mean age of the 63 patients was 65.4 years (range, $48-88$ years).

A skin incision was made along the midline of the knee and the joint was exposed through a medial parapatellar approach. Soft tissue release was performed depending on the extent of the deformity. The posterior cruciate ligament (PCL) was resected in all cases and a distal femoral cut preceded a proximal tibial cut. Femoral component size was determined with an anterior reference system and a rotation of the component using the transepicondylar axis. The angle of the proximal tibial cut was adjusted to reproduce the preoperative posterior tibial slope while taking care to avoid $\geq 15^{\circ}$ of the slope when measured by our method.

\section{Measurement Method}

Posterior tibial slope was measured on the lateral radiograph pre- and postoperatively. The preoperative posterior tibial slope was defined as the angle created by a line perpendicular to the anterior tibial cortex and a line parallel to the tibial plateau (Fig. 1). The postoperative posterior tibial slope was defined as the angle created by a line perpendicular to the anterior tibial cortex and a line parallel to the tibial component. The postoperative posterior tibial slope was measured from the radiograph taken immediately after surgery and there was no change in the postoperative slope in all cases during the follow-up period. The pre- and postoperative difference of the posterior tibial slope was calculated by subtracting the preoperative value from the postoperative value.

ROM was measured using a goniometer pre- and post-

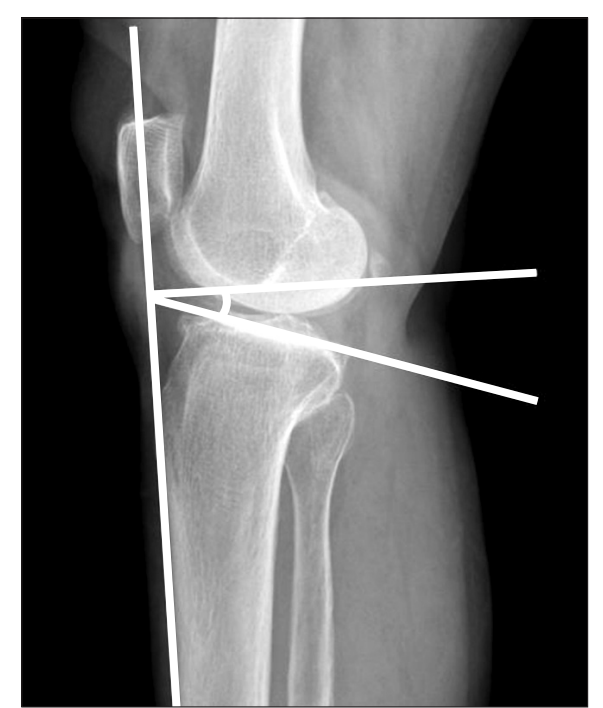

Fig. 1. A method of measuring the posterior tibial slope in this study. A horizontal line is drawn perpendicular to the anterior tibial cortex. A third line is drawn along the tibia plateau. The angle formed by the horizontal perpendicular line and the proximal tibial margin represents the slope angle.

operatively. The center of the goniometer was placed over the lateral epicondyle of the femur. One of the stationary arms was positioned parallel to the greater trochanter of the femur and the other to the lateral malleolus of the fibula. With the angle in full extension set as $0^{\circ}$, the increases in the angle was measured during knee flexion. The measurement was carried out by 10 experienced orthopedic surgeons, 1 for each year, between 2001 and 2010.

In knees with flexion contracture, the ROM was calculated by subtracting the flexion contracture angle from the maximal angle of flexion. Postoperative ROM was measured at the last follow-up (at $\geq 3$ years after surgery). The change in the maximal angle of flexion was calculated by subtracting the preoperative value from the postoperative value.

\section{Comparison}

The 79 cases were divided into two subsets: group A (44 cases with $\leq 10^{\circ}$ ) and group B ( 35 cases with $>10^{\circ}$ ) according to the mean postoperative posterior tibial slope, and group $\alpha$ (39 cases with $\leq-4^{\circ}$ ) and group $\beta$ (40 cases with $>-4^{\circ}$ ) according to the difference of the pre- and postoperative posterior tibial slope.

The postoperative maximal angle of flexion, along with the change in the pre- and postoperative maximal angle of flexion, were measured at the last follow-up (at $\geq 3$ years after surgery). Intergroup comparisons were done between group $\mathrm{A}$ and $\mathrm{B}$, and between group $\alpha$ and $\beta$. 
Table 1. Comparison of Preoperative Demographics between Group A and Group B

\begin{tabular}{lccc}
\hline & Group A & Group B & p-value \\
\hline Age $(y r)$ & $66.2(54-85)$ & $64.5(48-65)$ & 0.315 \\
Body mass index & $28.3(23.5-37.8)$ & $27.4(22.8-33.2)$ & 0.212 \\
Alignment & $10(1-19)$ & $11.5(4-19)$ & 0.624 \\
Flexion contracture & $8.4(0-20)$ & $8.1(0-20)$ & 0.831 \\
Further flexion & $127.2(90-150)$ & $129.9(100-150)$ & 0.480 \\
Range of motion & $118.8(90-150)$ & $121.8(90-150)$ & 0.477 \\
\hline
\end{tabular}

Table 2. Comparison of Preoperative Demographics between Group a and Group $\beta$

\begin{tabular}{lccc}
\hline & Group $\alpha$ & \multicolumn{1}{c}{ Group $\beta$} & p-value \\
\hline Age $(\mathrm{yr})$ & $66.4(54-85)$ & $64.5(48-65)$ & 0.259 \\
Body mass index & $28.3(23.5-37.8)$ & $27.6(22.8-33.2)$ & 0.310 \\
Alignment & $10.8(1-18)$ & $11.6(4-19)$ & 0.428 \\
Flexion contracture & $9.2(0-20)$ & $7.3(0-20)$ & 0.163 \\
Further flexion & $129.4(90-150)$ & $127.4(90-150)$ & 0.601 \\
Range of motion & $120.1(90-150)$ & $120.1(90-150)$ & 0.999 \\
\hline
\end{tabular}

\section{Statistical Analysis}

Statistical analysis was performed with SPSS ver. 12.0 (SPSS Inc., Chicago, IL, USA). Intergroup comparisons were performed using t-tests. Statistical significance was set at $\mathrm{p}<0.05$.

\section{Results}

The mean follow-up period was 6.1 years (range, 3-9 years). In the 79 cases, the mean postoperative posterior tibial slope was $10^{\circ}$ (range, $3^{\circ}-20^{\circ}$ ) and the mean pre-and postoperative change in the posterior tibial slope was $-3.8^{\circ}$ (range, $-22^{\circ}-8^{\circ}$ ).

The mean flexion contracture decreased significantly from $8.2^{\circ}$ (range, $0^{\circ}-20^{\circ}$ ) preoperatively to $1.4^{\circ}$ (range, $0^{\circ}-10^{\circ}$ ) postoperatively $(\mathrm{p}=0.000)$. No statistically significant preand postoperative change was found in the maximal angle of flexion. The mean ROM increased remarkably from $120.1^{\circ}$ (range, $90^{\circ}-150^{\circ}$ ) preoperatively to $128.4^{\circ}$ (range, $90^{\circ}-150^{\circ}$ ) postoperatively $(\mathrm{p}=0.002)$.

There was no significant difference between the groups in terms of age, body mass index (BMI), alignment, and ROM (Tables 1,2).

The mean postoperative maximal angle of flexion was not significantly different between group A $\left(129.2^{\circ}\right.$; range, $100^{\circ}$ $\left.150^{\circ}\right)$ and group $B\left(130.6^{\circ}\right.$; range, $\left.100^{\circ}-150^{\circ}\right)$, which were divided according to the mean postoperative posterior tibial slope $(p=0.667)$ (Table 3$)$. There was no significant intergroup
Table 3. Comparison of Postoperative Maximal Angle of Flexion and the Change of Maximal Angle of Flexion according to Postoperative Posterior Tibial Slope

\begin{tabular}{lccc}
\hline & Group A & Group B & p-value \\
\hline $\begin{array}{l}\text { Postoperative posterior } \\
\text { tibial slope }\end{array}$ & $8.1(3-10)$ & $12.9(11-20)$ & 0.000 \\
$\begin{array}{l}\text { Postoperative maximal } \\
\text { anlge of flexion }\end{array}$ & $129.2(100-150)$ & $130.6(100-150)$ & 0.667 \\
$\begin{array}{l}\text { The change of maximal } \\
\text { angle of flexion }\end{array}$ & $2(-50-60)$ & $0.7(-50-40)$ & 0.785 \\
\hline
\end{tabular}

Table 4. Comparison of Postoperative Maximal Angle of Flexion and the Change of Maximal Angle of Flexion according to the Difference between Preoperative Posterior Tibial Slope and Postoperative Posterior Tibial Slope

\begin{tabular}{lccc}
\hline & Group $\alpha$ & Group $\beta$ & p-value \\
\hline $\begin{array}{l}\text { The difference between } \\
\text { preoperative posterior } \\
\text { tibial slope and }\end{array}$ & $-8.7(-22--4)$ & $0.9(-3-8)$ & 0.000 \\
$\begin{array}{l}\text { postoperative posterior } \\
\text { tibial slope }\end{array}$ & & & \\
$\begin{array}{l}\text { Postoperative maximal } \\
\text { anlge of flexion }\end{array}$ & $129.4(100-150)$ & $130.3(100-150)$ & 0.777 \\
$\begin{array}{l}\text { The change of maximal } \\
\text { angle of flexion }\end{array}$ & $0(-50-35)$ & $2.9(-50-60)$ & 0.554 \\
\hline
\end{tabular}

difference in the mean change of pre- and postoperative maximal angle of flexion: $2^{\circ}$ (range, $-50^{\circ}-60^{\circ}$ ) in group $\mathrm{A}$ and $0.7^{\circ}$ (range, $\left.-50^{\circ}-40^{\circ}\right)$ in group $B(p=0.785)$.

The mean postoperative maximal angle of flexion was not significantly different between group a $\left(129.4^{\circ}\right.$; range, $\left.100^{\circ}-150^{\circ}\right)$ and group $\beta\left(130.3^{\circ}\right.$; range, $\left.100^{\circ}-150^{\circ}\right)$ that were divided according to the mean pre- and postoperative change of the posterior tibial slope ( $\mathrm{p}=0.777$ ) (Table 4). There was no significant intergroup difference in the mean change of the preand postoperative maximal angle of flexion: $0^{\circ}$ (range, $-50^{\circ}-35^{\circ}$ ) in group $\alpha$ and $2.9^{\circ}$ (range, $\left.-50^{\circ}-60^{\circ}\right)$ in group $\beta(p=0.554$ ).

\section{Discussion}

Postoperative ROM is an important indicator of the success of TKA, and there are various factors that may influence the postoperative ROM. In particular, posterior tibial slope has been considered positively correlated with the maximal angle of flexion ${ }^{14)}$. Braun et al. ${ }^{16)}$ reported posterior tibial slope would delay tibiofemoral impingement and recommended $6.5^{\circ}$ of posterior tibial slope to maximize the maximal angle of flexion. 
Increased posterior tibial slope results in an increase in PCL tension, especially after PCL-retaining TKA, which facilitates posterior femoral rollback and possibly knee flexion. However, Takatsu et al. ${ }^{15}$ warned that an excessive increase in the posterior tibial slope following PCL-retaining TKA could compromise the PCL function, which could eventually negate the advantages of the PCL-retaining procedure.

Studies on the relationship between the posterior tibial slope and the maximal angle of flexion have been hampered by the difficulty of excluding the influence of other ROM-related factors in the assessment of TKA results. Hence, studies based on real clinical data from TKA patients have been rare.

There have been some studies involving human cadavers or computer models to assess the relationship between the posterior tibial slope and the maximal angle of flexion. Bellemans et al. ${ }^{18)}$ analyzed 21 cadaver simulations of a PCL-retaining TKA using three-dimensional computer programs, and reported that a $1^{\circ}$ increase in the posterior tibial slope would improve an average of $1.7^{\circ}$ of the maximal angle of flexion. According to the study by Walker and $\mathrm{Garg}^{14)}$ using a computer simulation model of the knee joint and prosthesis, posterior tibial slope could increase the maximal angle of flexion. They documented that when the posterior tibial slope was $10^{\circ}$, the maximal flexion angle increased by $30^{\circ}$, and when the anterior tibial slope was $10^{\circ}$, the maximal flexion angle decreased by $25^{\circ}$. Massin and Gournay ${ }^{20)}$ investigated the relationship between the tibia and femur when the knee is in flexion using the lateral radiographs of the knee. The study showed that a 3-mm decrease of the posterior condylar offset could reduce the knee flexion by $10^{\circ}$ before the occurrence of tibiofemoral impingement. In addition, a $5^{\circ}$ decrease in the posterior tibial slope could reduce the knee flexion by an additional $5^{\circ}$.

In the abovementioned studies, the independent influence of the posterior tibial slope on the maximal angle of flexion was assessed by controlling other various factors that may affect the ROM. Therefore, we could formulate a hypothesis that the posterior tibial slope would be positively correlated with maximal angle of flexion. The purpose of the present study was to test the hypothesis by analyzing the real clinical data from TKA patients.

Kansara and Markel ${ }^{19)}$ reported that there was no significant relationship between the posterior tibial slope and ROM in their TKA patients. They divided the patients into two groups according to the use of either a $0^{\circ}$ or $5^{\circ}$ proximal tibial cutting block and could not find significant intergroup differences in the postoperative ROM. However, the study had some limitations in assessing the independent influence of the posterior tibial slope on the maximal angle of flexion because other variables that could affect the ROM were not controlled. In another study based on clinical data, Malviya et al. ${ }^{21)}$ divided TKA patients into 3 groups according to the posterior tibial slope $\left(\leq 5^{\circ},>5^{\circ}\right.$ and $<8^{\circ}$, and $\left.\geq 8^{\circ}\right)$, and found that the posterior tibial slope was correlated with maximal angle of flexion. Although other variables were taken into consideration in the study, the 12-month follow-up period was relatively short to yield accurate results.

We controlled potentially confounding variables including the surgeon, surgical technique, surgical equipment, preoperative flexion contracture and ROM, varus/valgus deformity, and postoperative follow-up period. There were no significant differences between the groups in terms of age, BMI, alignment and ROM. Therefore, we could perform an independent assessment on the influence of the posterior tibial slope on the maximal angle of flexion. In addition, flexion angle measurement was performed at $\geq 3$ years after surgery when the postoperative condition was sufficiently stable. Contrary to our hypothesis, the results showed no significant relationship between the posterior tibial slope and the maximal angle of flexion.

There were some limitations of this study. First, the number of cases $(n=79)$ was small due to the stringent exclusion criteria, which accordingly might have reduced the statistical power of the intergroup comparison. When the type 1 error was set at 0.05 and the effect size was set at 7 , the significant difference in the maximal angle of flexion between two groups based on previous studies, the type 2 error was 0.4 , which indicates that the statistical power of this study was 0.6 . Therefore, we think that securing a maximum number of initial cases would be conducive to obtaining a high statistical power even with a strict control of variables.

Second, there could have been measurement errors. A total of 10 observers measured the ROM using a goniometer. Goniometers have been considered as a reliable ROM measurement device ${ }^{22}$. However, it has been recommended to employ the same experienced observer for all measurements throughout a study to improve the interobserver reliability of goniometric measuremt ${ }^{23)}$. Although all of the observers were experienced surgeons in the present study, the employment of 10 different observers during the study period between 2001 and 2010 might have impacted the reliability of the measurements. Therefore, we recommend that all measurements are taken by the same experienced observer or based on the lateral radiographs taken with the knee in full extension or full flexion to obtain more accurate study results.

In spite of these limitations, the significance of this study can 
be described as follows: The study was based on real clinical data obtained from our TKA patients, the confounding variables were more rigorously controlled compared to the previous studies, and the evaluation was performed at a sufficient interval after surgery. Therefore, we could assess the influence of the posterior tibial slope on the maximal angle of flexion in a highly independent and accurate manner. We believe our study results would serve as a useful reference for determining the posterior tibial slope in TKA.

It is our understanding that the independent influence of posterior tibial slope on the maximal angle of flexion can be assessed more precisely in studies that involve a more strict control of the variables that may affect the maximal angle of flexion and a larger study population.

\section{Conclusions}

The ROM was improved after TKA in patients with knee arthritis. On the other hand, no statistically significant improvement was noted in the postoperative maximal angle of flexion.

In addition, the postoperative posterior tibial slope was not correlated with the maximal angle of flexion.

\section{Acknowledgements}

This study was supported by a grant (2009-470) from the Asan Institute for Life Sciences, Seoul, Korea.

\section{References}

1. Cross WW 3rd, Saleh KJ, Wilt TJ, Kane RL. Agreement about indications for total knee arthroplasty. Clin Orthop Relat Res. 2006;446:34-9.

2. Ritter MA, Campbell ED. Effect of range of motion on the success of a total knee arthroplasty. J Arthroplasty. 1987;2:957.

3. Schurman DJ, Parker JN, Ornstein D. Total condylar knee replacement. A study of factors influencing range of motion as late as two years after arthroplasty. J Bone Joint Surg Am. 1985;67:1006-14.

4. Maloney WJ, Schurman DJ. The effects of implant design on range of motion after total knee arthroplasty. Total condylar versus posterior stabilized total condylar designs. Clin Orthop Relat Res. 1992;(278):147-52.

5. Parsley BS, Engh GA, Dwyer KA. Preoperative flexion. Does it influence postoperative flexion after posterior-cruciateretaining total knee arthroplasty? Clin Orthop Relat Res. 1992;(275):204-10.

6. Harvey IA, Barry K, Kirby SP, Johnson R, Elloy MA. Factors affecting the range of movement of total knee arthroplasty. J Bone Joint Surg Br. 1993;75:950-5.

7. Anouchi YS, McShane M, Kelly F Jr, Elting J, Stiehl J. Range of motion in total knee replacement. Clin Orthop Relat Res. 1996;(331):87-92.

8. Lizaur A, Marco L, Cebrian R. Preoperative factors influencing the range of movement after total knee arthroplasty for severe osteoarthritis. J Bone Joint Surg Br. 1997;79:626-9.

9. Schurman DJ, Matityahu A, Goodman SB, Maloney W, Woolson S, Shi H, Bloch DA. Prediction of postoperative knee flexion in Insall-Burstein II total knee arthroplasty. Clin Orthop Relat Res. 1998;(353):175-84.

10. Kawamura H, Bourne RB. Factors affecting range of flexion after total knee arthroplasty. J Orthop Sci. 2001;6:248-52.

11. Ritter MA, Harty LD, Davis KE, Meding JB, Berend ME. Predicting range of motion after total knee arthroplasty. Clustering, log-linear regression, and regression tree analysis. J Bone Joint Surg Am. 2003;85:1278-85.

12. Sultan PG, Most E, Schule S, Li G, Rubash HE. Optimizing flexion after total knee arthroplasty: advances in prosthetic design. Clin Orthop Relat Res. 2003;(416):167-73.

13. Whiteside LA, Amador DD. The effect of posterior tibial slope on knee stability after Ortholoc total knee arthroplasty. J Arthroplasty. 1988;3 Suppl:S51-7.

14. Walker PS, Garg A. Range of motion in total knee arthroplasty. A computer analysis. Clin Orthop Relat Res. 1991;(262):227-35.

15. Takatsu T, Itokazu M, Shimizu K, Brown TD. The function of posterior tilt of the tibial component following posterior cruciate ligament-retaining total knee arthroplasty. Bull Hosp Jt Dis. 1998;57:195-201.

16. Braun V, Biasca N, Romero J. Factors influencing postoperative flextion after mobile bearing total knee arthroplasty. J Bone Joint Surg Br. 2001;83 Suppl 2:133.

17. Jojima H, Whiteside LA, Ogata K. Effect of tibial slope or posterior cruciate ligament release on knee kinematics. Clin Orthop Relat Res. 2004;(426):194-8.

18. Bellemans J, Robijns F, Duerinckx J, Banks S, Vandenneucker $\mathrm{H}$. The influence of tibial slope on maximal flexion after total knee arthroplasty. Knee Surg Sports Traumatol Arthrosc. 2005;13:193-6. 
19. Kansara D, Markel DC. The effect of posterior tibial slope on range of motion after total knee arthroplasty. J Arthroplasty. 2006;21:809-13.

20. Massin P, Gournay A. Optimization of the posterior condylar offset, tibial slope, and condylar roll-back in total knee arthroplasty. J Arthroplasty. 2006;21:889-96.

21. Malviya A, Lingard EA, Weir DJ, Deehan DJ. Predicting range of movement after knee replacement: the importance of posterior condylar offset and tibial slope. Knee Surg
Sports Traumatol Arthrosc. 2009;17:491-8.

22. Gogia PP, Braatz JH, Rose SJ, Norton BJ. Reliability and validity of goniometric measurements at the knee. Phys Ther. 1987;67:192-5.

23. Watkins MA, Riddle DL, Lamb RL, Personius WJ. Reliability of goniometric measurements and visual estimates of knee range of motion obtained in a clinical setting. Phys Ther. 1991;71:90-6. 